2016 - Volume: 17 Number: 2

Page: 377 - 389

DOI : $10.18038 /$ btda. 21961

Received: 08 March 2016

Revised: 18 May 2016 Accepted: 13 June 2016

\title{
THE SYNTHESIS OF ALLYL GLYCIDYL ETHER COPOLYMERS AND THEIR THERMOKINETIC ANALYSIS
}

\author{
Yeliz YILDIRIM \\ Department of Chemistry, Faculty of Sciences, Ege University, Bornova, İzmir, 35100, Turkey
}

\begin{abstract}
The copolymerization reactions of allyl glycidyl ether (AGE) by radicalic polymerization under argon atmosphere using benzoyl peroxide (BPO) as an initiator with the comonomers of allyl methacrylate (AMA) and methyl methacrylate (MMA) were studied. The synthesized copolymers were characterized by nuclear magnetic resonance ( $\left.{ }^{1} \mathrm{H}-\mathrm{NMR}\right)$, gel permeation chromatography (GPC), Fourier transform infrared spectroscopy (FTIR) and thermogravimetric analysis (TG). FTIR and ${ }^{1} \mathrm{H}$ NMR spectra showed that the pendant epoxy groups in copolymers remained throughout the copolymerization of AGE. The apparent activation energies for thermal degradation of the copolymers were calculated from their TG data by using FlynnWall-Ozawa (FWO), Kissinger-Akahira-Sunose (KAS) and Coats-Redfern methods. The kinetic parameter (pre-exponential factor) and Thermodynamic parameters such as Gibbs energy, enthalpy and entropy were also calculated by Coats-Redfern method. The activation energies calculated by KAS method for Poly(AGE-co-AMA) and Poly(AGE-co-MMA) were found to be $292 \pm 10 \mathrm{~kJ} / \mathrm{mol}$ and $175 \pm 27 \mathrm{~kJ} / \mathrm{mol}$ for the first stage, and $252 \pm 74 \mathrm{~kJ} / \mathrm{mol}$ and $232 \pm 32 \mathrm{~kJ} / \mathrm{mol}$ for the second, respectively while they were $361 \pm 1 \mathrm{~kJ} / \mathrm{mol}$ and $249 \pm 61 \mathrm{~kJ} / \mathrm{mol}$ for Poly(AGE-co-AMA) and $136 \pm 24 \mathrm{~kJ} / \mathrm{mol}$ and $278 \pm 18$ $\mathrm{kJ} / \mathrm{mol}$ for Poly(AGE-co-MMA) by FWO method.
\end{abstract}

The most likely mechanisms of the main degradation stages were determined as $\boldsymbol{F}_{3}$ model for Poly(AGE-Co-AMA) and Poly(AGE-co-MMA). Thus, it is concluded that the thermal degradations of Poly(AGE-co-AMA) and Poly(AGE-co-MMA) copolymers exhibit similar behavior.

Keywords: Thermal degradation, Allyl glycidyl ether, Allyl methacrylate, Methyl methacrylate

\section{INTRODUCTION}

Epoxy resins combine good thermal and dimensional stability, excellent chemical and corrosion resistance, high tensile strength and modulus, and ease of handling and processability, ensuring their wide applications to industrial fields such as coatings, adhesives and insulating materials [1-4]. Many attempts have been made in developing advanced technologies in order to improve the thermal properties of the high-performance epoxy resins [2]. Allyl glycidyl ether has a conjugated epoxy group and an unconjugated allylic group. Because of their higher reactivities, bifunctional monomers containing two reactive groups can be used for the preparation of functional (co)polymers. The thermal degradation behaviors of the epoxy containing homo- and copolymers have been discussed previously [5-8]. Investigating the degradation of the polymers is of importance in understanding their processing, application, and thermal recycling. The common methods of polymer degradation are bio-, photo-oxidative, ozone-induced, mechanochemical, thermal and catalytic degradations [9-13].

In the present study, the thermal degradation kinetics of the epoxy containing Poly(AGE-co-AMA) and Poly(AGE-co-MMA) copolymers synthesized by radicalic polymerization were investigated to compare their thermal properties since the thermal properties of which are very important from the viewpoint of their usages. For this purpose, the apparent activation energies for thermal degradation of the copolymers were determined by using FWO, KAS and Coats-Redfern methods. Also the kinetic and thermodynamic parameters (pre-exponential factor, Gibbs energy, enthalpy, and entropy) and the degradation mechanism of the copolymers were also studied by Coats-Redfern method. 


\subsection{Kinetic Analysis [14-16]}

Thermogravimetric analysis can be used for determining the degradation kinetics of a lot of polymers. In general, the thermal degradation reaction of a solid polymer can be shown as:

$$
\mathrm{A}_{\text {solid }} \rightarrow \mathrm{B}_{\text {solid }}+\mathrm{C}_{\text {gas }}
$$

where $\mathrm{A}$ is the starting material, $\mathrm{B}_{\text {solid }}$ and $\mathrm{C}_{\text {gas }}$ are the solid residue and the gas product, respectively.

The thermal degradation kinetics of the polymers is generally expressed by the following typical kinetic equation

$$
r=\frac{d \alpha}{d t}=k(T) \times f(\alpha)
$$

where $T$ is the absolute temperature $(K)$; $r$ is the conversion per unit time $(t)$ and $f(\alpha)$ is the conversion function which represents the reaction model. The degree of conversion $(\alpha)$ is calculated by Eq. (2) where $\mathrm{m}_{\mathrm{o}}, \mathrm{m}_{\mathrm{t}}$ and $\mathrm{m}_{\mathrm{f}}$ are the weights of sample before degradation, at time $\mathrm{t}$ and after complete degradation, respectively.

$$
\alpha=\frac{m_{0}-m_{t}}{m_{0}-m_{f}}
$$

$\mathrm{k}$ is the reaction constant which can be expressed by the Arrhenius equation:

$$
k(T)=A_{0} e^{-\left(\frac{E_{a}}{R T}\right)}
$$

where $\mathrm{A}$ is called pre-exponential factor, $\mathrm{E}_{\mathrm{a}}$ is the activation energy and $\mathrm{R}$ is the gas constant. By combining Eq. (1) and Eq. (3) the following equation is obtained

$$
\frac{d \alpha}{d t}=A_{0} e^{-\left(\frac{E_{a}}{R T}\right)} \times f(\alpha)
$$

According to the kinetic theory for the non-isothermal decomposition reactions, the fractional conversion $\alpha$ is expressed as a function of temperature which depends on the time of heating. Thus the heating rate $(\beta)$ can be described as:

$$
\beta=\frac{d T}{d t}
$$

that Eq. (4) is modified as follows:

$$
\frac{d \alpha}{d T}=\left(\frac{1}{\beta}\right) A_{0} e^{-\left(\frac{E_{a}}{R T}\right)} \times f(\propto)
$$

Eq. (4) and Eq. (6) are the basis for the many equations derived to evaluate thermal analysis data.

\subsubsection{Flynn-Wall-Ozawa (FWO) method $[17,18]$}

The activation energy can be determined by this method with no need of any knowledge for the reaction mechanism. The pre-exponential factor $(A)$ and the activation energy $\left(E_{a}\right)$ are not dependent on the fraction of degradation while they are on the temperature. This method uses Eq. (7). 
Yıldırım / Anadolu Univ. J. of Sci. and Technology - A - Appl. Sci. and Eng. 17 (2) - 2016

$$
\log g(\alpha)=\log \left(\frac{A E_{a}}{R}\right)-\log \beta+\log p\left(\frac{E_{a}}{R T}\right)
$$

Eq. (8) is obtained by means of the Doyle approximation.

$$
\log \beta=\log \left(\frac{A E_{a}}{R}\right)-\log g(\alpha)-2,315-0,4567\left(\frac{E_{a}}{R T}\right)
$$

Hence, from the slope $-E_{a} / R$ of the linear plot of $\log \beta$ versus $1000 / T, E_{a}$ is readily obtained.

\subsubsection{Kissinger-Akahira-Sunose (KAS) method $[19,20]$}

The KAS method is based on the following equation

$$
\ln \left(\frac{\beta}{T^{2}}\right)=\ln \frac{A R}{E_{a} g(\alpha)}-\left(\frac{E_{a}}{R T}\right)
$$

where the plots of $\ln \left(\beta / T^{2}\right)$ versus $1000 / T$ for the several $\alpha$ values give straight lines with the slope of $-E_{\mathrm{a}} / \mathrm{R}$ which give the corresponding $\mathrm{E}_{\mathrm{a}}$ values.

\subsubsection{Coats-Redfern method [21]}

This method is based on the following equation

$$
\ln \left(\frac{g(\alpha)}{T^{2}}\right)=\ln \left(\frac{A R}{E_{a} \beta}\left(\frac{1-2 R T}{E_{a}}\right)\right)-\left(\frac{E_{a}}{R T}\right)
$$

as $E_{a}$ is calculated from the slope $-E_{a} / R$ of the plot $\ln \left(g(\alpha) / T^{2}\right)$ versus $1000 / T$ which is a straight line. The possible thermal degradation mechanism can also be estimated from the most commonly used

\begin{tabular}{|c|c|c|c|}
\hline Symbol & Reaction model & $\mathbf{f}(\boldsymbol{\alpha})$ & $\mathbf{g}(\alpha)$ \\
\hline \multicolumn{4}{|c|}{ Sigmoidal curves } \\
\hline$A_{2}$ & $\begin{array}{l}\text { Avrami-Erofěev }(\mathrm{n}=2) \\
\text { (Nucleation and growth) }\end{array}$ & $2(1-\alpha)[-\ln (1-\alpha)]^{1 / 2}$ & {$[-\ln (1-\alpha)]^{1 / 2}$} \\
\hline$A_{3}$ & $\begin{array}{l}\text { Avrami-Erofěev }(\mathrm{n}=3) \\
\text { (Nucleation and growth) }\end{array}$ & $3(1-\alpha)[-\ln (1-\alpha)]^{-1 / 2}$ & {$[-\ln (1-\alpha)]^{1 / 3}$} \\
\hline$A_{4}$ & $\begin{array}{l}\text { Avrami-Erofěev }(\mathrm{n}=4) \\
\text { (Nucleation and growth) }\end{array}$ & $4(1-\alpha)[-\ln (1-\alpha)]^{-1 / 3}$ & {$[-\ln (1-\alpha)]^{1 / 4}$} \\
\hline \multicolumn{4}{|c|}{ Deceleration curves } \\
\hline$R_{1}$ & $\begin{array}{l}\text { Zero-order (Polany-Winger equation) } \\
\text { Phase-boundary controlled reaction } \\
\text { (one dimensional movement) }\end{array}$ & 1 & $\alpha$ \\
\hline $\boldsymbol{R}_{2}$ & $\begin{array}{l}\text { Phase-boundary controlled reaction } \\
\text { (contracting area, i.e., bidimensional shape) }\end{array}$ & $2(1-\alpha)^{1 / 2}$ & {$\left[1-\ln (1-\alpha)^{1 / 2}\right]$} \\
\hline $\boldsymbol{R}_{3}$ & $\begin{array}{l}\text { Phase-boundary controlled reaction } \\
\text { (contracting area, i.e., bidimensional shape) }\end{array}$ & $3(1-\alpha)^{2 / 3}$ & {$\left[1-\ln (1-\alpha)^{1 / 3}\right]$} \\
\hline$F_{1}$ & $\begin{array}{l}\text { First-order (Mampel) } \\
\text { (Random nucleation with two nuclei on the }\end{array}$ & $(1-\alpha)$ & $\ln (1-\alpha)$ \\
\hline
\end{tabular}
reaction models for the solid-state processes listed in Table 1[16].

Table 1 Algebraic expressions of $f(\alpha)$ and $g(\alpha)$ for the reaction models [16] considered in the present work 
Yıldırım / Anadolu Univ. J. of Sci. and Technology - A - Appl. Sci. and Eng. 17 (2) - 2016

\begin{tabular}{|c|c|c|c|}
\hline & individual particle) & & \\
\hline $\boldsymbol{F}_{2}$ & $\begin{array}{l}\text { Second-order } \\
\text { (Random nucleation with two nuclei on the } \\
\text { individual particle) }\end{array}$ & $(1-\alpha)^{2}$ & $1 /(1-\alpha)$ \\
\hline $\boldsymbol{F}_{3}$ & $\begin{array}{l}\text { Third-order } \\
\text { (Random nucleation with two nuclei on the } \\
\text { individual particle) }\end{array}$ & $1 / 2(1-\alpha)^{3}$ & $1 /(1-\alpha)^{2}$ \\
\hline$D_{1}$ & One-dimensional diffusion & $1 / 2 \alpha$ & $\alpha^{2}$ \\
\hline$D_{2}$ & $\begin{array}{l}\text { Two-dimensional diffusion (bidimensional } \\
\text { particle shape) Valensi equation }\end{array}$ & $-1 /[\ln (1-\alpha)]$ & $(1-\alpha) \ln (1-\alpha)+\alpha$ \\
\hline$D_{3}$ & $\begin{array}{l}\text { Three-dimensional diffusion } \\
\text { (tridimensional particle shape) Jander } \\
\text { equation }\end{array}$ & $\begin{array}{c}3(1-\alpha)^{2 / 3} / 2[1- \\
\left.(1-\alpha)^{-1 / 3}\right]\end{array}$ & {$\left[1-\ln (1-\alpha)^{1 / 3}\right]^{2}$} \\
\hline$D_{4}$ & $\begin{array}{l}\text { Three-dimensional diffusion } \\
\text { (tridimensional particle shape) Ginstling- } \\
\text { Brounshtein }\end{array}$ & $3 / 2\left[(1-\alpha)^{-1 / 3}-1\right]$ & $(1-2 \alpha / 3)-(1-\alpha)^{2 / 3}$ \\
\hline
\end{tabular}

\section{EXPERIMENTAL}

\subsection{MATERIALS}

Allyl glycidyl ether (AGE), methyl methacrylate (MMA) and allyl methacrylate (AMA) with the purities of 97, 99 and 98 percent, respectively, as it is with all other chemicals, purchased from Merck A.G (Germany). They were used without any further purification.

\subsection{Copolymerization}

$10 \mathrm{mmol}$ of AGE and comonomer (MMA or AMA) and $0.1 \mathrm{mmol}$ of benzoyl peroxide (BPO) were placed into a pyrex flask. The polymerization was carried out at $70^{\circ} \mathrm{C}$ for 2 hours under argon atmosphere. The solid copolymers were precipitated pouring the polymer solution into methanol.

\subsection{Characterization of the Copolymers}

FTIR spectra of the copolymers were taken on Perkin Elmer Spectrum 100 FT-IR Spectrometer (USA) using $\mathrm{KBr}$ pellets. ${ }^{1} \mathrm{H}-\mathrm{NMR}$ spectra of the copolymers were taken in $\mathrm{CDCl}_{3}$ as solvent by means of a Varian $400 \mathrm{MHz}$ NMR Spectrometer (USA). Molecular weights were determined by gel permeation chromatography (GPC) instrument equipped with a Waters (USA) styragel column (HR series 2, 3, 5E) with tetrahydrofuran as the eluent at a flow rate of $0.3 \mathrm{~mL} / \mathrm{min}$ and a Waters 410 differential refractometer detector. The TG curves were recorded by using a Perkin Elmer, Diamond TG/DTA(USA). The samples were heated under argon atmosphere over a temperature range 30 to $600^{\circ} \mathrm{C}$ with heating rates of $5,10,15,20^{\circ} \mathrm{C} / \mathrm{min}$. The weight loss (TG curve) and its first derivative (DTG curve) vs. temperature were recorded simultaneously. The solid sample weights for all the experiments were taken in the range of $8-10 \mathrm{mg}$.

\section{RESULTS AND DISCUSSION}

\subsection{Characterization of the Copolymers}

Poly(AGE-co-AMA) and Poly(AGE-co-MMA) were synthesized by copolymerization of AGE with AMA and MMA as comonomers in bulk at $70^{\circ} \mathrm{C}$, in the presence of $\mathrm{BPO}$ as initiator. It was proved by FTIR (Figure 1) and ${ }^{1} \mathrm{H}-\mathrm{NMR}$ (Figure 2) spectroscopy that the polymerization has occurred. As seen in Fig 1, the FTIR absorption bands for $\mathrm{C}=\mathrm{O}$ bond of the Poly(AGE-co-AMA) and Poly(AGEco-MMA) copolymers take place around $1700 \mathrm{~cm}^{-1}$ while the characteristic strong absorption band of the ether group appears at $1100 \mathrm{~cm}^{-1}$, and two bands for C-H bending appear at 1233 and $855 \mathrm{~cm}^{-1}$. As 
far as ${ }^{1} \mathrm{H}-\mathrm{NMR}$ spectra are concerned Poly(AGE-co-MMA) exhibits characteristic peaks for $\mathrm{CH}_{3}$ protons between 0.5 and $1.0 \mathrm{ppm}$. Additionally, $\mathrm{CH}_{3}-\mathrm{O}$ protons were detectable as a sharp signal at 3.7 ppm. ${ }^{1} \mathrm{H}-\mathrm{NMR}$ spectrum of Poly(AGE-co-AMA) was not achieved because a suitable solvent was not found to solve it.

$\mathrm{M}_{\mathrm{n}}$ (number-average molecular weight) and the polydispersity index (PDI) of the Poly(AGE-coMMA) was measured by GPC as the results are $65000 \mathrm{~g} / \mathrm{mol}$ for $\mathrm{M}_{\mathrm{n}}$, and 2.30 for PDI, respectively. The molecular weight of Poly(AGE-co-AMA) copolymer was not achieved because a suitable solvent was not found to solve it. Molecular weight of Poly(AGE-Co-AMA) was not determined because of solubility problem.
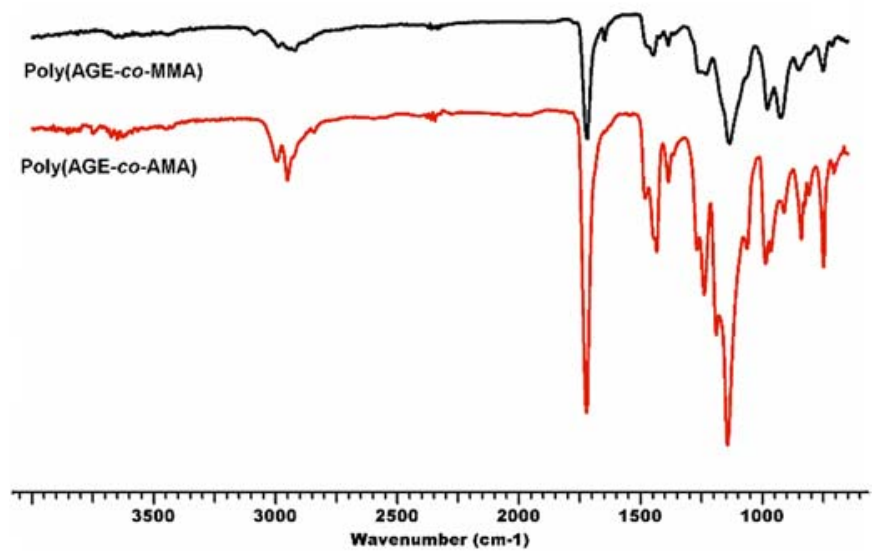

Figure 1. FTIR spectra of Poly(AGE-co-AMA) and Poly(AGE-co-MMA)

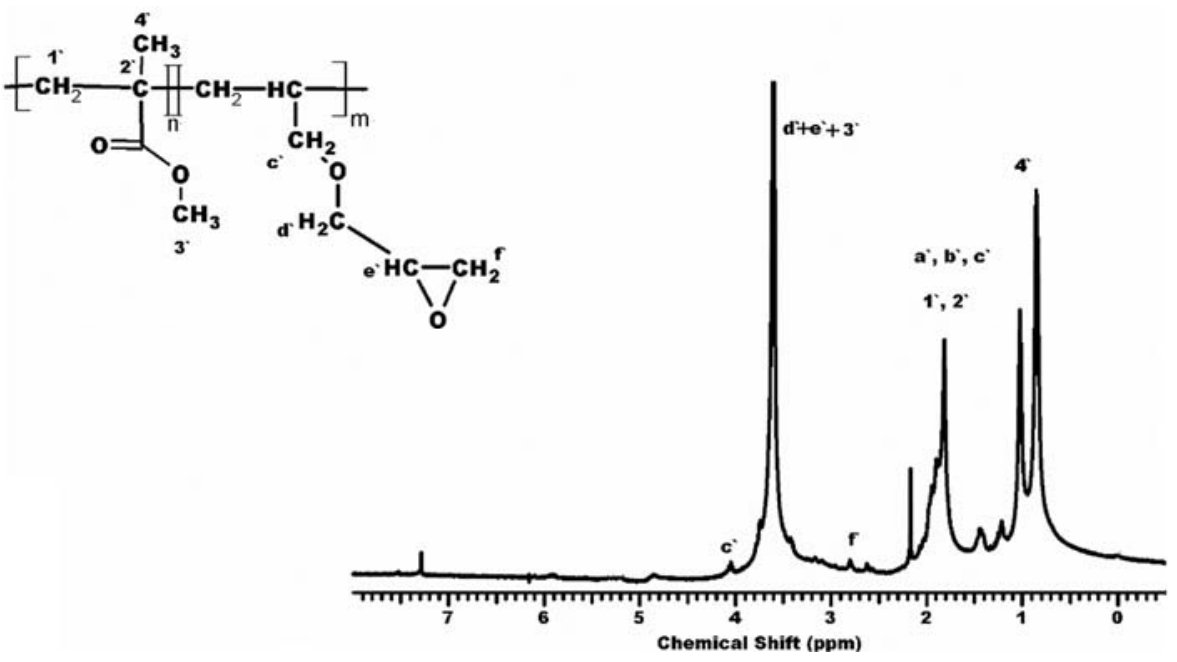

Figure 2. ${ }^{1} \mathrm{HNMR}$ spectrum of Poly(AGE-co-MMA)

\subsection{Thermogravimetric Analysis of the Copolymers}

Fig. 3 and 4 show the respective TG and DTG thermograms of Poly(AGE-co-AMA) and Poly(AGEco-MMA) under argon atmosphere over a temperature range 30 to $600^{\circ} \mathrm{C}$ with a heating rate of $10^{\circ} \mathrm{C} / \mathrm{min}$. The initial $\left(\mathrm{T}_{\mathrm{i}}\right)$, maximum $\left(\mathrm{T}_{\max }\right)$ and final $\left(\mathrm{T}_{\mathrm{f}}\right)$ degradation temperatures related to the thermograms are summarized in Table 2. 
Yıldırım / Anadolu Univ. J. of Sci. and Technology - A - Appl. Sci. and Eng. 17 (2) - 2016

Table 2. Initial $\left(T_{i}\right)$, maximum $\left(T_{\max }\right)$, and final $\left(T_{f}\right)$ degradation temperatures for the thermal degradation of the copolymers

\begin{tabular}{ccccccc}
\hline \multirow{2}{*}{ Copolymer } & \multicolumn{2}{c}{$\mathbf{T}_{\mathbf{i}}\left({ }^{\circ} \mathbf{C}\right)$} & \multicolumn{2}{c}{$\mathbf{T}_{\max }\left({ }^{\circ} \mathbf{C}\right)$} & \multicolumn{2}{c}{$\mathbf{T}_{\mathbf{f}}\left({ }^{\circ} \mathbf{C}\right)$} \\
& $\begin{array}{c}\text { First } \\
\text { stage }\end{array}$ & $\begin{array}{c}\text { Main } \\
\text { stage }\end{array}$ & $\begin{array}{c}\text { First } \\
\text { stage }\end{array}$ & $\begin{array}{c}\text { Main } \\
\text { stage }\end{array}$ & $\begin{array}{c}\text { First } \\
\text { stage }\end{array}$ & $\begin{array}{c}\text { Main } \\
\text { stage }\end{array}$ \\
\hline Poly(AGE-co-AMA) & 250 & 350 & 305 & 420 & 350 & 497 \\
Poly(AGE-co-MMA) & 175 & 253 & 172 & 382 & 240 & 452 \\
\hline
\end{tabular}

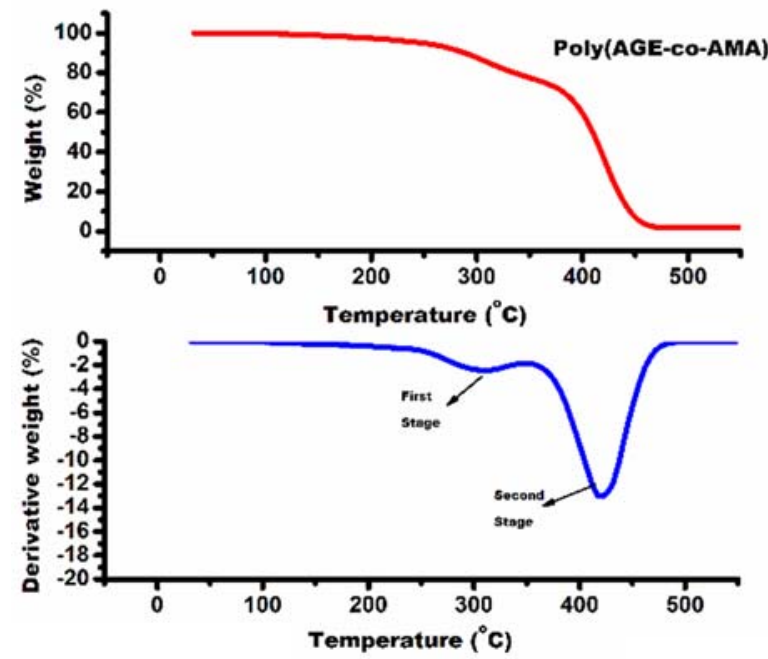

Figure 3. The TG and DTG thermograms of Poly(AGE-co-AMA) in argon atmosphere at $10{ }^{\circ} \mathrm{C} / \mathrm{min}$

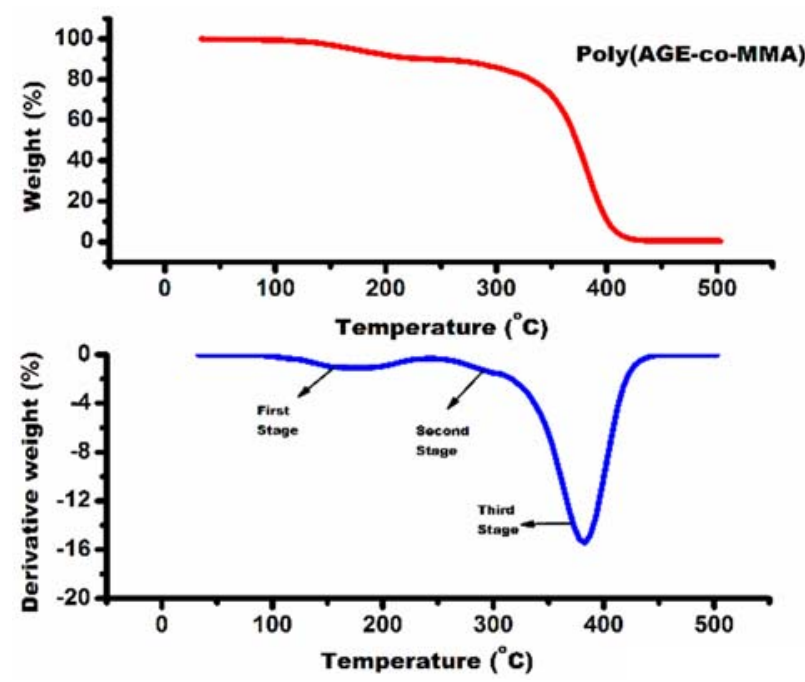

Figure 4. The TG and DTG thermograms of Poly(AGE-co-MMA) in argon atmosphere at $10{ }^{\circ} \mathrm{C} / \mathrm{min}$

The thermogram of Poly(AGE-co-AMA) exhibited the copolymer has degraded in two stages. The $\mathrm{T}_{\max }$ was about $420^{\circ} \mathrm{C}$ while the half-life temperature $\left(\mathrm{T}_{1 / 2}\right)$ was about $409^{\circ} \mathrm{C}$. The similar thermal degradation behavior has been reported for Poly(allyl methacrylate) (PAMA) by Vardarel, et. al. and Zulfiqar et. al. [22, 23] as $\mathrm{T}_{\max }$ and $\mathrm{T}_{1 / 2}$ being around $409^{\circ} \mathrm{C}$ and $400^{\circ} \mathrm{C}$, respectively. Solpan et al. has reported $\mathrm{T}_{\max }$ and $\mathrm{T}_{1 / 2}$ for Poly(allyl glycidyl ether) (PAGE) homopolymer to be $443^{\circ} \mathrm{C}$ and $434^{\circ} \mathrm{C}$, 
respectively [24]. A residue of about $5.0 \%$ remained over $600^{\circ} \mathrm{C}$ for PAGE, while PAMA and Poly(AGE-co-AMA) degraded completely at this temperature. Thus, the degradation temperatures of the AGE copolymer with AMA seems to decrease average $25^{\circ} \mathrm{C}$ compared to that of PAGE homopolymer indicating that the copolymer is less stable than the homopolymer. However the degradation temperatures of the copolymer are quite similar to those of PAMA homopolymer i.e. both having the same stability. According to the TG data, various products such as $\mathrm{CO}, \mathrm{CO}_{2},-\mathrm{CN},-\mathrm{CH}_{2}-$ $\mathrm{CH}=\mathrm{CH}_{2},-\mathrm{O}-\mathrm{CH}_{2}-\mathrm{CH}=\mathrm{CH}_{2},-\mathrm{C}(=\mathrm{O})-\mathrm{O}-\mathrm{CH}_{2}-\mathrm{CH}=\mathrm{CH}_{2}$, anhydride structures and also the monomer are obtained in the two stage degradation of PAMA [22]. The first degradation stage of Poly(AGE-CoAMA) in the range of 250 to $350^{\circ} \mathrm{C}$ may be due to the destruction of carbonyl units and methacrylate groups which are more sensitive to degradation while the second degradation stage in the range of 350 to $497^{\circ} \mathrm{C}$ is possibly because of the degradation of polymer chain itself.

As far as thermal degradation of Poly(AGE-co-MMA) is concerned, two degradation stages are observed again with the weight losses of $6 \%$ and $94 \%$ for first and second (main) stages, respectively. The thermal degradation of the radiation induce synthesized Poly(AGE-co-MMA) has also been reported to occur in two stages as described earlier [24]. The $T_{\max }$ of the second stage for Poly(AGE-co-MMA) and $\mathrm{T}_{1 / 2}$ were found to be $403^{\circ} \mathrm{C}$ and $390^{\circ} \mathrm{C}$, respectively. In the present work $\mathrm{T}_{\max }$ and $\mathrm{T}_{1 / 2}$ were found to be $383^{\circ} \mathrm{C}$ and $372^{\circ} \mathrm{C}$. The differences in the values may arise due to the different copolymerization methods.

Very weak peak with $\mathrm{T}_{\max }=175^{\circ} \mathrm{C}$ is observed in the DTG curves of Poly(AGE-co-MMA) over the temperature range 100 to $230^{\circ} \mathrm{C}$ with the weight losses of $3 \%$. It was reported that the PMMA obtained by radicalic polymerization may contain some head to head linkages and some early degradation which occur around $140-150^{\circ} \mathrm{C}$ is due to the cease of these linkages because the bond dissociation energy of such bonds is low in comparison to that of the $\mathrm{C}-\mathrm{C}$ bonds mainly due to steric and inductive effects of vicinal ester groups. The second degradation stage which occurs around 230$255^{\circ} \mathrm{C}$ seems due to the unsaturated chain ends resulting from the termination by disproportionation $[25,26]$. The degradation stage in present work is a very weak peak with $\mathrm{T}_{\max }$ around $255^{\circ} \mathrm{C}$. The thermal degradation in both the first and second stage leading to a weight loss of nearly $5-6 \%$ ends before approximately $360^{\circ} \mathrm{C}$ where the third and main stage of degrading process involving random scission starts.

In order to obtain detailed information related to the thermal stability of the copolymers the kinetic and thermodynamic parameters such as activation energy, pre-exponential factor, Gibbs energy, enthalpy and entropy of the degradation were calculated using FWO, KAS and Coats-Redfern methods. Also the degradation kinetics of the main degradation stage was investigated to determine the degradation mechanism. First FWO and KAS methods were used to analyze the TG data of Poly(AGE-co-AMA) and Poly(AGE-co-MMA) because they were independent of any thermal degradation mechanism. Then the results obtained were compared with that of Coats-Redfern method to conclude the true mechanism and to find out the rest of the kinetic and thermodynamic parameters.

\subsection{Thermal Degradation Kinetics of the Copolymers}

Poly(AGE-co-AMA) and Poly(AGE-co-MMA) were heated thermogravimetrically under various heating rates such as $5,10,15$, and $20^{\circ} \mathrm{C} / \mathrm{min}$ in a temperature range of 30 to $600^{\circ} \mathrm{C}$ to determine their thermal degradation mechanisms and the activation energies. The TG curves obtained for the copolymers are shown in Fig. 5 and 6, respectively. The individual degradation behavior of each copolymer was analogous at all heating rates as seen from the figure. The apparent activation energies and thermal degradation models for the copolymers were estimated by FWO, KAS and Coats-Redfern. 


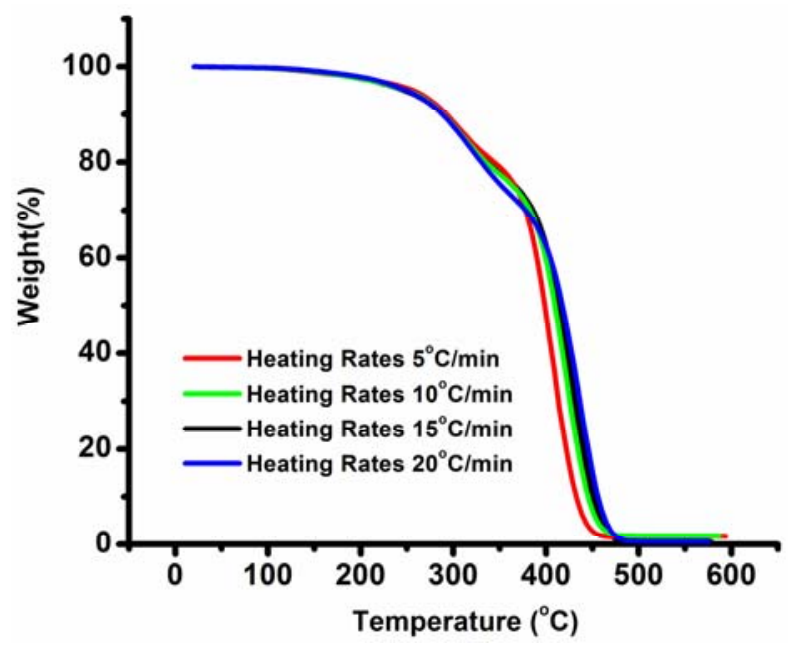

Figure 5. The TG thermograms of Poly(AGE-co-AMA) in argon atmosphere at different heating rates $\left(5,10,15,20^{\circ} \mathrm{C} / \mathrm{min}\right)$

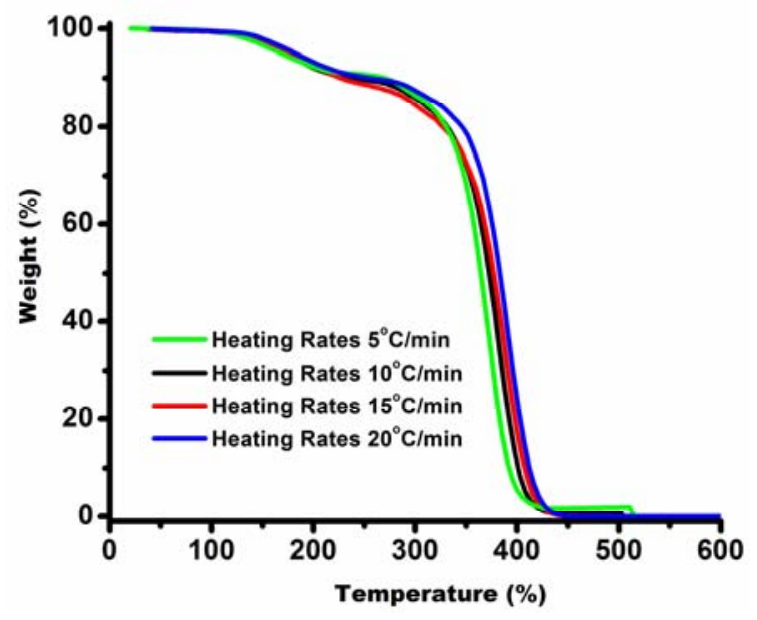

Figure 6. The TG thermograms of Poly(AGE-co-MMA) in argon atmosphere at different heating rates $\left(5,10,15,20^{\circ} \mathrm{C} / \mathrm{min}\right)$

The activation energies for Poly(AGE-co-AMA) and Poly(AGE-co-MMA) were found to be $361 \pm 1$ and $136 \pm 24$ for the first, and $249 \pm 61$ and $278 \pm 18$ for the second (main) stage, respectively by means of the classical FWO method. The average activation energies were calculated by KAS method for Poly(AGE-co-AMA) and Poly(AGE-co-MMA) as $292 \pm 10$ and $175 \pm 27$ for the first, and $252 \pm 74$ and $232 \pm 32$ for the second (main) stages, respectively. The calculated activation energies for Poly(AGEco-AMA) and Poly(AGE-co-MMA) seem to be pretty higher than that of PAGE which is $72 \mathrm{~kJ} / \mathrm{mol}[24]$.

The plot of $E_{a} v s$. the degree of conversion is commonly used to indicate the degradation mechanism, i.e., it is one-step or more. As shown in Fig. 7, the mechanism changes throughout the degradation since $E_{a}$ for Poly(AGE-co-AMA) exhibits varying values between 360 and $180 \mathrm{~kJ} / \mathrm{mol}$ which means that Poly(AGE-co-AMA) has a complex degradation mechanism. The variation of the activation energies for the copolymer as a function of the degree of conversion (Fig. 8) showed that $E_{a}$ increased up to $40 \%$ for Poly(AGE-co-MMA) then remained practically constant. The increase in the $E_{a}$ values as a function of $\alpha$ is attributed essentially to thermally more stable structures because of the crosslinking reactions occurred during the progress of the thermal degradation [27]. 


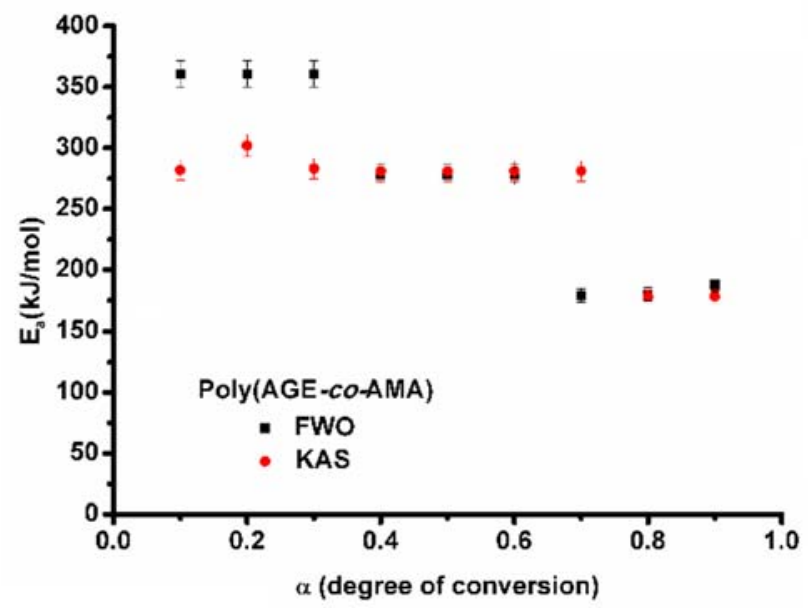

Figure 7. The plot of activation energy $\left(E_{a}\right)$ vs. the degree of conversion $(\alpha)$ for Poly(AGE-co-AMA)

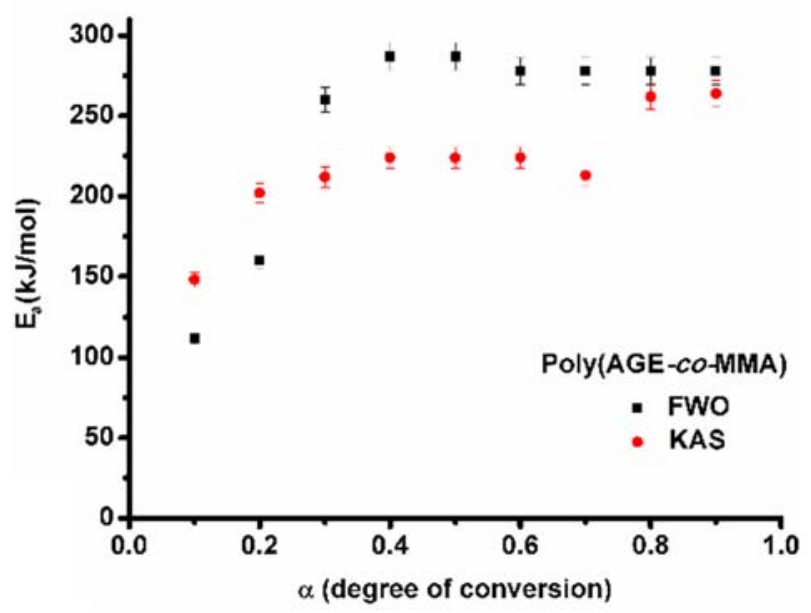

Figure 8. The plot of activation energy $\left(\mathrm{E}_{\mathrm{a}}\right)$ vs. the degree of conversion $(\alpha)$ for Poly(AGE-co-MMA)

The thermal degradation mechanism of the copolymers for the main degradation stage is confirmed by

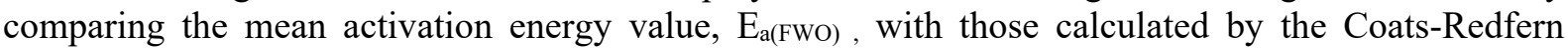
method for different models in Table 1. The activation energies and correlations obtained from CoatsRedfern method at different heating rates are represented in Table 3 and 4 . The $E_{a}$ calculated from the $\boldsymbol{F}_{3}$ model is nearly the same with $\mathrm{E}_{\mathrm{a}(\mathrm{FWO})}$ for Poly(AGE-Co-AMA) being $249 \mathrm{~kJ} / \mathrm{mol}$ which leads to a conclusion that the most probable mechanism for the thermal degradation of Poly(AGE-co-AMA) is the third-order, $\boldsymbol{F}_{3}$ (random nucleation with two nuclei on the individual particle) for the heating rate of $15{ }^{\circ} \mathrm{C} / \mathrm{min}$.

Thermal degradation kinetics of Poly(AGE-co-MMA) copolymer shows that the activation energy obtained by FWO method is in good agreement with that of $\boldsymbol{F}_{3}$ model for the heating rate of $15^{\circ} \mathrm{C} / \mathrm{min}$. Consequently, the solid-state degradation mechanism of Poly(AGE-co-AMA) and Poly(AGE-co-MMA) have the same mechanism (integral form $1 /(1-\alpha)^{2}$ for $F_{3}$ ). 
Yıldırım / Anadolu Univ. J. of Sci. and Technology - A - Appl. Sci. and Eng. 17 (2) - 2016

Table 3. The degradation activation energies of Poly(AGE-co-AMA) calculated by Coats-Redfern method for different heating rates $\left(5,10,15,20^{\circ} \mathrm{C} / \mathrm{min}\right)$

\begin{tabular}{|c|cc|cc|cc|cc|}
\hline $\begin{array}{c}\boldsymbol{\beta} \\
\left({ }^{\mathbf{o}} \mathbf{C} / \mathbf{m i n}\right)\end{array}$ & \multicolumn{2}{|c}{$\mathbf{5}$} & & \multicolumn{2}{|c|}{$\mathbf{1 0}$} & \multicolumn{2}{|c|}{$\mathbf{1 5}$} & \multicolumn{2}{|c|}{$\mathbf{2 0}$} \\
\cline { 2 - 9 } Symbol & Main stage & \multirow{2}{*}{$\mathrm{R}^{2}$} & $\begin{array}{c}\text { Main stage } \\
\mathbf{E}_{\mathbf{a}}(\mathbf{k J J} / \mathbf{m} / \mathbf{m o l})\end{array}$ & $\mathrm{R}^{2}$ & $\begin{array}{c}\text { Main stage } \\
\mathbf{E}_{\mathbf{a}}(\mathbf{k J} / \mathbf{m o l})\end{array}$ & $\mathrm{R}^{2}$ & $\begin{array}{c}\text { Main stage } \\
\mathbf{E}_{\mathbf{a}}(\mathbf{k J} / \mathbf{m o l})\end{array}$ & $\mathrm{R}^{2}$ \\
\hline $\boldsymbol{A}_{\mathbf{2}}$ & 121 & 0.992 & 110 & 0.992 & 104 & 0.972 & 98 & 0.969 \\
$\boldsymbol{A}_{\mathbf{3}}$ & 121 & 0.992 & 110 & 0.992 & 104 & 0.972 & 98 & 0.969 \\
$\boldsymbol{A}_{\mathbf{4}}$ & 121 & 0.992 & 110 & 0.992 & 104 & 0.972 & 98 & 0.969 \\
$\boldsymbol{R}_{\mathbf{1}}$ & 63 & 0.964 & 57 & 0.974 & 54 & 0.988 & 51 & 0.980 \\
$\boldsymbol{R}_{\mathbf{2}}$ & 40 & 0.992 & 38 & 0.994 & 37 & 0.996 & 36 & 0.996 \\
$\boldsymbol{R}_{\mathbf{3}}$ & 32 & 0.993 & 31 & 0.995 & 31 & 0.997 & 29 & 0.997 \\
$\boldsymbol{D}_{\mathbf{1}}$ & 137 & 0.970 & 125 & 0.978 & 120 & 0.990 & 113 & 0.984 \\
$\boldsymbol{D}_{\mathbf{2}}$ & 166 & 0.984 & 152 & 0.987 & 145 & 0.993 & 137 & 0.989 \\
$\boldsymbol{D}_{\mathbf{3}}$ & 53 & 0.983 & 50 & 0.992 & 48 & 0.996 & 47 & 0.995 \\
$\boldsymbol{D}_{\mathbf{4}}$ & 47 & 0.963 & 44 & 0.950 & 42 & 0.941 & 41 & 0.947 \\
$\boldsymbol{F}_{\mathbf{1}}$ & 121 & 0.992 & 110 & 0.982 & 104 & 0.972 & 98 & 0.969 \\
$\boldsymbol{F}_{\mathbf{2}}$ & 140 & 0.874 & 125 & 0.836 & 116 & 0.794 & 110 & 0.791 \\
$\boldsymbol{F}_{\mathbf{3}}$ & 292 & 0.883 & 261 & 0.847 & $\mathbf{2 4 4}$ & 0.809 & 231 & 0.807 \\
\hline
\end{tabular}

Table 4. The degradation activation energies of Poly(AGE-co-MMA) calculated by Coats-Redfern method for different heating rates $\left(5,10,15,20^{\circ} \mathrm{C} / \mathrm{min}\right)$

\begin{tabular}{|c|c|c|c|c|c|c|c|c|}
\hline \multirow{2}{*}{$\begin{array}{c}\beta \\
\left({ }^{\circ} \mathrm{C} / \mathrm{min}\right) \\
\text { Symbol }\end{array}$} & \multicolumn{2}{|l|}{5} & \multicolumn{2}{|c|}{10} & \multicolumn{2}{|l|}{15} & \multicolumn{2}{|c|}{20} \\
\hline & $\begin{array}{l}\text { Main stage } \\
E_{a}(k J / m o l)\end{array}$ & $\mathrm{R}^{2}$ & $\begin{array}{l}\text { Main stage } \\
\mathrm{E}_{\mathrm{a}}(\mathrm{kJ} / \mathrm{mol})\end{array}$ & $\mathrm{R}^{2}$ & $\begin{array}{l}\text { Main stage } \\
E_{a}(k J / m o l)\end{array}$ & $\mathrm{R}^{2}$ & $\begin{array}{l}\text { Main stage } \\
\mathrm{E}_{\mathrm{a}}(\mathrm{kJ} / \mathrm{mol})\end{array}$ & $\mathrm{R}^{2}$ \\
\hline$A_{2}$ & 127 & 0.997 & 126 & 0.991 & 126 & 0.988 & 136 & 0.988 \\
\hline$A_{3}$ & 127 & 0.997 & 126 & 0.991 & 126 & 0.988 & 136 & 0.988 \\
\hline$A_{4}$ & 127 & 0.997 & 126 & 0.991 & 126 & 0.988 & 136 & 0.988 \\
\hline$R_{1}$ & 66 & 0.945 & 66 & 0.974 & 66 & 0.981 & 71 & 0.940 \\
\hline$R_{2}$ & 41 & 0.988 & 38 & 0.985 & 41 & 0.996 & 43 & 0.983 \\
\hline$R_{3}$ & 32 & 0.989 & 33 & 0.995 & 33 & 0.997 & 34 & 0.985 \\
\hline$D_{1}$ & 142 & 0.953 & 144 & 0.978 & 144 & 0.984 & 152 & 0.949 \\
\hline$D_{2}$ & 172 & 0.973 & 174 & 0.989 & 173 & 0.993 & 185 & 0.967 \\
\hline$D_{3}$ & 54 & 0.983 & 54 & 0.993 & 54 & 0.995 & 57 & 0.978 \\
\hline$D_{4}$ & 48 & 0.977 & 48 & 0.959 & 47 & 0.953 & 51 & 0.966 \\
\hline$F_{1}$ & 127 & 0.997 & 126 & 0.991 & 126 & 0.988 & 136 & 0.988 \\
\hline$F_{2}$ & 149 & 0.909 & 144 & 0.836 & 143 & 0.843 & 159 & 0.899 \\
\hline$F_{3}$ & 308 & 0.914 & 300 & 0.865 & 297 & 0.852 & 329 & 0.905 \\
\hline
\end{tabular}

\subsection{Determination of Pre-Exponential Factor}

The pre-exponential factor (A) was calculated by Coats-Redfern method from the solid-state degradation for each of the mechanisms obtained for the copolymers as shown in Table 5 and 6.

In the Coats-Redfern method told about, $\ln \mathrm{A}$ is calculated from the intersection of the $\mathrm{y}$ axis (when $\mathrm{x}=0 \quad \mathrm{y}=\ln \mathrm{AR} / \beta \mathrm{E}_{\mathrm{a}}$ neglecting $\left.(1-2 \mathrm{RT} / \mathrm{E})\right)$ using Equation 10 [28].

\subsection{Determination of Enthalpy, Entropy and Gibbs Energy of Activation}

The thermal degradation parameters i.e. activation enthalpy $\left(\Delta \mathrm{H}^{\ddagger}\right)$, entropy $\left(\Delta \mathrm{S}^{\ddagger}\right)$ and Gibbs energy $\left(\Delta \mathrm{G}^{\ddagger}\right)$ are calculated using Equations 11, 12, and 13, respectively [29].

$$
E_{a}=\Delta H^{\neq}-\mathbf{R} T_{\max }
$$




$$
\begin{gathered}
A=\frac{k T_{\text {max }}}{h} e^{\Delta S^{\ddagger}-R T_{\text {max }}} \\
\Delta G^{\neq}=\Delta H^{\neq}-T_{\text {max }} \Delta S^{\neq}
\end{gathered}
$$

where $\mathrm{k}$ is Boltzmann constant, $\mathrm{h}$ is Planck constant and $\mathrm{T}_{\max }$ is the temperature related to DTG peak maximum. All kinetic and thermodynamic parameters of the thermal degradation calculated from the thermogravimetric curves for the conversions in main degradation stage are listed in Table 5 and 6.

The activation enthalpy is positive because the degradation is an endothermic process for both of the copolymers. The positive sign of $\Delta \mathrm{G}^{\neq}$indicates that the degradation of the related copolymer is nonspontaneous. All $\mathrm{E}_{\mathrm{a}}, \Delta \mathrm{H}^{\neq}, \Delta \mathrm{G}^{\neq}$and $\Delta \mathrm{S}^{\neq}$are positive for Poly(AGE-co-AMA) and Poly(AGEco-MMA) at $\mathrm{T}_{\max }$ which refers to the fact that the degradation is nonspontaneous while it is spontaneous at higher temperatures than $T_{\max }$ because $T_{\max } \Delta \mathrm{S}^{\neq}, \Delta \mathrm{H}^{\ddagger}$ and consequently $\Delta \mathrm{G}^{\neq}$is negative as readily seen in Eq.13.

Table 5. Pre-exponential factor (A), activation enthalpy $\left(\Delta \mathrm{H}^{\ddagger}\right)$, entropy $\left(\Delta \mathrm{S}^{\ddagger}\right)$ and Gibbs energy $\left(\Delta \mathrm{G}^{\neq}\right)$of Poly(AGE-co-AMA) obtained by Coats-Redfern method for $\boldsymbol{F}_{3}$ model (main degradation stage) at $15^{\circ} \mathrm{C} / \mathrm{min}$

\begin{tabular}{cccccc}
\hline Stage & Symbol & $\begin{array}{c}\text { Pre-exponential } \\
\text { factor } \\
\mathbf{A}(/ \mathbf{m i n})\end{array}$ & $\begin{array}{c}\Delta \mathbf{H}^{\neq} \\
(\mathbf{k J} / \mathbf{m o l})\end{array}$ & $\begin{array}{c}\Delta \mathbf{S}^{\neq} \\
(\mathbf{k J} / \mathbf{m o l ~ K})\end{array}$ & $\begin{array}{c}\Delta \mathbf{G}^{\neq} \\
(\mathbf{k J} / \mathbf{m o l})\end{array}$ \\
\hline Main stage & $\mathbf{F}_{3}$ & $1.93 \times 10^{19}$ & 250 & 0,117 & 169 \\
\hline
\end{tabular}

Table 6. Pre-exponential factor (A), activation enthalpy $\left(\Delta \mathrm{H}^{\ddagger}\right)$, entropy $\left(\Delta \mathrm{S}^{\ddagger}\right)$ and Gibbs energy $\left(\Delta G^{\neq}\right)$of Poly(AGE-co-MMA) obtained by Coats-Redfern method for $\boldsymbol{F}_{3}$ model (main degradation stage) at $15^{\circ} \mathrm{C} / \mathrm{min}$.

\begin{tabular}{cccccc}
\hline Stage & Symbol & $\begin{array}{c}\text { Pre-exponential } \\
\text { factor } \\
\mathbf{A}(/ \mathbf{m i n})\end{array}$ & $\begin{array}{c}\Delta \mathbf{H}^{\neq} \\
(\mathbf{k J} / \mathbf{m o l})\end{array}$ & $\begin{array}{c}\Delta \mathbf{S}^{\neq} \\
(\mathbf{k J} / \mathbf{m o l ~ K})\end{array}$ & $\begin{array}{c}\Delta \mathbf{G}^{\neq} \\
(\mathbf{k J} / \mathbf{m o l})\end{array}$ \\
\hline Main stage & $\mathrm{F}_{3}$ & $1.08 \times 10^{25}$ & 302 & 0.317 & 94 \\
\hline
\end{tabular}

\section{CONCLUSIONS}

The kinetics of thermal degradation of AGE copolymers were studied and discussed. The activation energies calculated by KAS method for Poly(AGE-co-AMA) and Poly(AGE-co-MMA) were found to be $292 \pm 10 \mathrm{~kJ} / \mathrm{mol}$ and $175 \pm 27 \mathrm{~kJ} / \mathrm{mol}$ for the first stage, and $252 \pm 74 \mathrm{~kJ} / \mathrm{mol}$ and $232 \pm 32 \mathrm{~kJ} / \mathrm{mol}$ for the second, respectively while they were $361 \pm 1 \mathrm{~kJ} / \mathrm{mol}$ and $249 \pm 61 \mathrm{~kJ} / \mathrm{mol}$ for Poly(AGE-co-AMA) and $136 \pm 24 \mathrm{~kJ} / \mathrm{mol}$ and $278 \pm 18 \mathrm{~kJ} / \mathrm{mol}$ for Poly(AGE-co-MMA) by FWO method.

The activation energies determined by KAS and FWO methods indicate that the thermal stabilities exhibit an order of Poly(AGE-co-AMA) $>$ (Poly(AGE-co-MMA). Poly(AGE-co-AMA) copolymer has significantly higher $\mathrm{E}_{\mathrm{a}}$ value than that of Poly(AGE-co-MMA) probably due to crosslinking during its polymerization. Both of the thermal degradation mechanisms of the main degradation stages of Poly(AGE-co-AMA) and Poly(AGE-co-MMA) obtained from Coats-Redfern method seem to be a random nucleation with two nuclei on the individual particle which is known as $\boldsymbol{F}_{3}$ model.

All thermodynamic parameters, namely $\mathrm{E}_{\mathrm{a}}, \Delta \mathrm{H}^{\neq}, \Delta \mathrm{G}^{\neq}$and $\Delta \mathrm{S}^{\ddagger}$ are shown to be positive as a result of kinetic analysis of the thermal degradation of Poly(AGE-co-AMA) and Poly(AGE-co-MMA) which consequently implies that the thermal degradation is spontaneous at higher temperatures. 


\section{REFERENCES}

[1] Xu K, Chen M, Zhang K, Hu J. Synthesis and characterization of novel epoxy resin bearing naphthyl and limonene moieties, and its cured polymer, Polymer, 45:1133-1140, 2004.

[2] Zabihia O, Mostafavi SM, Ravari F, Khodabandeh A, Hooshafza A, Zare K, Shahizadeh M. The effect of zinc oxide nanoparticles on thermo-physical properties of diglycidyl ether of bisphenol A/2,2'-Diamino-1,1'-binaphthalene nanocomposites, Thermochimica acta, 521:49-58, 2011.

[3] Liu Y, Liu W, Yu D. Thermal properties and flame retardancy of epoxy resins modified with polysiloxane containing epoxy groups and redistributed Poly(2,6-dimethyl-1,4-phenylene) chains, Iranian Polymer Journal, 18:445-452, 2009.

[4] Gao JG, Zhang X, Huo Li. Curing kinetics and thermal properties of liquid crystalline pPEPB/Bisphenol-A Epoxy/Diamine system, Iranian Polymer Journal, 19:731-742, 2010.

[5] Hsiue GH, Wei HF, Shiao SJ, Kuo WJ, Sha YA. Chemical modification of dicyclopentadienebased epoxy resins to improve compatibility and thermal properties, Polymer Degradation and Stability, 73:309-318, 2001.

[6] Budrugeac P, Segal E. Application of isoconversional and multivariate non-linear regression methods for evaluation of the degradation mechanism and kinetic parameters of an epoxy resin, Polymer Degradation and Stability, 93:1073-1080, 2008.

[7] Lin ST, Huang SK. Thermal degradation study of siloxane-DGEBA epoxy copolymers, European Polymer Journal, 33:365-373, 1997.

[8] Ghaemy M, Rahpaima G, Behmadi H. Effect of triphenylphosphine on the cure reaction and thermal stability of diglycidyl ether of bisphenol A-based epoxy resin, Iranian Polymer Journal, 17:875-885, 2008.

[9] Sivalingam G, Madras G. Thermal degradation of binary physical mixtures and copolymers of poly(E-caprolactone), poly(D,L-lactide), poly(glycolide), Polymer Degradation and Stability, 84:393398, 2004.

[10] Aoyagi Y, Yamashita K, Doi Y. Thermal degradation of poly[(R)-3-hydroxybutyrate], poly[عcaprolactone], and poly[(S)-lactide], Polymer Degradation and Stability, 76:53-59, 2002.

[11] Sivalingam G, Madras G. Thermal degradation of poly ( $\varepsilon$-caprolactone), Polymer Degradation and Stability, 80:11-16, 2003.

[12] Singh B, Sharma N. Mechanistic implications of plastic degradation, Polymer Degradation and Stability, 93:561-584, 2008.

[13] Rakhshani M, Kamrannejad MM, Babaluo AA, Rezaei M, Aghjeh MR. Thermal degradation behavior and kinetic studies of polyacrylamide gel in $\mathrm{TiO}_{2}$ nanoparticles synthesis, Iranian Polymer Journal, 21:821-828, 2012.

[14] Lee S, Jin BS, Lee JW. Thermal degradation kinetics of antimicrobial agent, Poly(hexamethylene guanidine) phosphate, Macromolecular Research, 14:491-498, 2006. 
[15] Wang D, Das A, Leuteritz A, Boldt R, Häußler L, Wagenknecht U, Heinrich G. Thermal degradation behaviors of a novel nanocomposite based on polypropylene and $\mathrm{Co}-\mathrm{Al}$ layered double hydroxide, Polymer Degradation and Stability, 96:285-290, 2011.

[16] Huadong W, Jie Y, Shengru L, Xiaojun W, Zheng Y, Guangxian L. Studies on the thermal degradation of poly(phenylene sulfide sulfone), Polymer Degradation and Stability, 83:229-235, 2004.

[17] Flynn JH, Wall LA. A quick direct method for the determination of activation energy from thermogravimetric data, Journal of Polymer Science Part B: Polymer Letters, 4:323-328, 1966.

[18] Ozawa T. A new method of analyzing thermogravimetric data, Bulletin of the Chemical Society of Japan, 38:1881-1886, 1965.

[19] Kissinger HE. Reaction kinetics in differential thermal analysis, Analytical Chemistry, 29:17021706, 1957.

[20] Akahira T, Sunose T. Joint convention of four electrical institutes, Research report (Chiba Institute of Technology) Sci Technol., 16:22-31, 1971.

[21] Coats AW, Redfern JP. Kinetic parameters from thermogravimetric data, Nature, 201, 68-69, 1964.

[22] Vardareli TK, Keskin S, Usanmaz A. Synthesis and characterization of poly(allyl methacrylate) obtained by free radical initiator, Journal of Macromolecular Science Part A: Pure and Applied Chemistry, 45:302-311, 2008.

[23] Zulfigar S, Piracha A, Masud K. The thermal degradation of poly(allyl methacrylate), Polymer Degradation and Stability, 52:89-93, 1996.

[24] Solpan D, Guven O. Thermal stability of the copolymers of allyl glycidyl ether with acrylonitrile and methyl methacrylate obtained via gamma irradiation, Radiation Physics and Chemistry, 57:173$177,2000$.

[25] Krul LP, Yakimtsova LB, Egorova EL, Matusevich YI, Selevich KA, Kurtikova AL, Preparation and Thermal Degradation of Methyl Methacrylate-Methacrylic Acid Copolymers, Russian Journal of Applied Chemistry, 82:1636-1643, 2009.

[26] Ahmad Z, Al-Awadi NA, Al-Sagheer F. Thermal degradation studies in poly(vinyl chloride)/poly(methyl methacrylate) blends, Polymer Degradation and Stability, 93:456-465, 2008.

[27] Schmidt V, Soldi V. Influence of polycaprolactone-triol addition on thermal stability of soy protein isolate based films, Polymer Degradation and Stability, 91:3124-3130, 2006.

[28] Yildirim Y, Doğan B, Muğlalı S, Saltan F, Özkan M, Akat H. Synthesis, characterization, and thermal degradation kinetic of Polystyrene-g-Polycaprolactone, Journal of Applied Polymer Science, 126:1236-1246, 2012.

[29] Faria EA, Prado AGS. Kinetic studies of the thermal degradation of cellulose acetate/niobium and chitosan/niobium composites, Reactive and Functional Polymers, 67:655-661, 2007. 